\title{
USE OF LANDSAT-SERIES DATA IN NATIONAL GEOGRAPHIC CONDITION MONITORING IN CHINA
}

\author{
BAI Jie ${ }^{a}$, ZHAO Yali ${ }^{a,}$, Sheng Lin ${ }^{a, b}$, LI Yingcheng ${ }^{a}$, LV Guijun $^{a}$ \\ $a$ *.China TOPRS Technology Co., Ltd, Beijing 100039, China, 8801215zyl@163.com; \\ b. Henan Polytechnic University School of Surveying and Land Information Engineering, Henan Jiaozuo 454000, \\ China,shenglin417@163.com;
}

KEY WORDS: long time series; geographical conditions monitoring; indicator system; temporal and spatial variation

\begin{abstract}
To fully grasp the nature and human geography situation information, solve the problem of ecological environment, economic and social development of the country, monitoring the state of geographic condition by uniform index system has great significance. By collecting the existing standard documents, our paper established a suit of index system considering the characteristics of long time series remote sensing data. The index system includes basic, subject, composite statistical indexes, and statistical indexes based on basic geographic element. The spatial and temporal distribution of geographic condition with Landsat TM image in Haidian district of Beijing from 1983 to 2013 are studies. Results show that farmland decreases by $28.60 \%$, build-up land increases by $38.95 \%$ in this period. The amount of land resources in different elevation/slope shows that, with the increase of elevation/slope, farmland and build-up land is gradually reduced, while grassland area is gradually increasing. In plains areas of elevation less than $50 \mathrm{~m}$ and within the scope of the 0 to $3^{\circ}$ slope, farmland and build-up land are the main land cover types, and both show the characteristic of tradeoffs. Urban area extended to the west and the north, meanwhile mass center of Haidian also moves to the northwest. The urban compactness decreases and the fractal index increased gradually, reflecting the city saturation degree become reduced, the city boundary becomes complicated gradually. The comprehensive land cover dynamic degree after the first decrease and then increases. Finally, based on the above statistic results, the spatial distribution of land cover in 2015 is predicted.
\end{abstract}

\section{INTRODUCTION}

Promoted by social needs and technology development, the national geographic condition monitoring becomes an important mission in better serving the country's sustainable economic and social development in China. A supplement to the short history of high spatial resolution data, Landsat data supplies a much longer record of our earth, which also has the ability to detect the variation of geographic condition. Monitoring index system and related technical method suit for Landsat-series data are strongly required, which are help to realize the data sharing mechanism, and serve to the national strategic decision making and planning (Shi, 2013).

\section{STUDY AREA AND DATA}

The study area is located in HaiDian District, Beijing, covers an area of $\sim 430 \mathrm{~km}^{2}$. The elevation increases from about $50 \mathrm{~m}$ for the eastern plain area to $1300 \mathrm{~m}$ in the western mountain area $(\mathrm{Yu}$, 2010). Landsat-series data were obtained from the Landsat archive

*Zhaoyali.Email:880215zyl@163.com (http://glovis.usgs.gov/) between 1983 and 2013, besides the year of 1985, 2008 and 2012 for cloudy. After the geometric processing, all Landsat data were classified into six different land cover types, including crop, forest, grass, build-up area, water and undeveloped land.

\section{RESEARCH METHOD}

By collecting the standard documents used in land resources investigation, ecology, environment, meteorology and such kinds of related regions, the indexes can be measured by satellite data are extracted and analyzed. Combined with the spatial, temporal and spectral characteristics of Landsat data, a systematic index system suitable for National geographic condition monitoring in China has been constructed, including the following four kinds of statistical indexes: basic, subject, composite statistical indexes, and statistical indexes based on basic geographic element.

The basic statistical indexes make a fundamental statistics of landform, the ratio of different land cover type, as well as the scope and circumference of build-up area. The calculation of the basic statistical indexes helps to detect the temporal-spatial 
variation of all the land cover types and fundamental characteristics.

The subject statistical indexes are aimed at the three mainly land covers types directly relating to sustainable economic and social development, which are vegetation, build-up area and wetland. For vegetation subject, the indexes mainly concentrated in descripting the spatial distribution and dynamic expanding characteristics. For build-up area, the dynamic expanding and its reasonability are quantified. While for wetland, the indexes focus on the variation of ecological construction and spatial distribution.

Composite statistical indexes are used to analyze the change rules and variation trend of six different land cover types based on landsat-series data, which can be used to serve the national strategic decision making and planning. While the CA-MARKOV (Cellular Automata-Markov) model is used for prediction.

Statistical indexes based on basic geographic element point at the ratio of different land cover types, which is used to recognize the dynamic variation for the specific region, benefiting for local distinctive development.
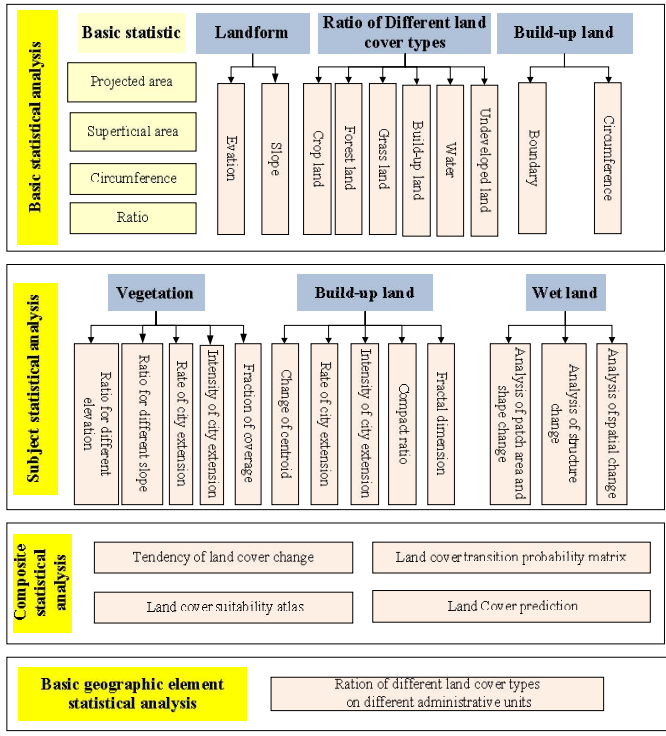

Figure.1 Index system for national condition monitoring

\section{RESULTS}

\subsection{BASIC STATISTICAL INDEXES}

\subsubsection{Landform}

The maximum elevation of Haidian District is $1261 \mathrm{~m}$, locates in the western area, the region with elevation less than $50 \mathrm{~m}$ are mainly distributed over eastern plain area, occupied more than $55 \%$ of Haidian District. The slope variation of Haidian District is between 0 to $58^{\circ}$, and its spatial distribution tendency is similarly to elevation (Figure 2).
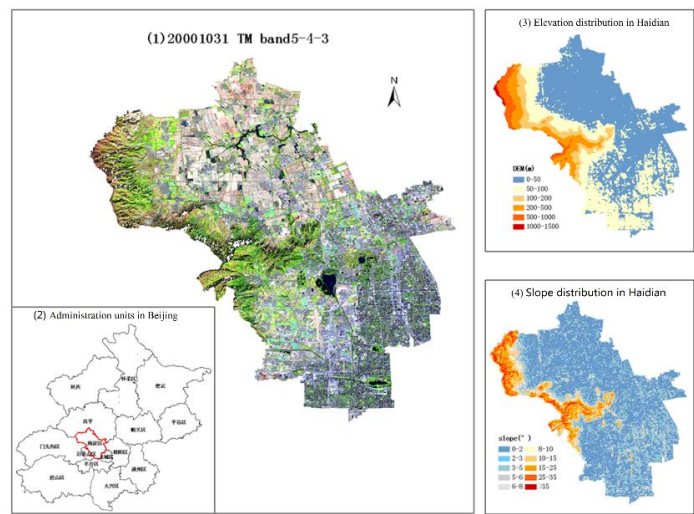

Figure.2 Landform information in Haidian

Table 1 Basic Statistical of landform in Haidian District

\begin{tabular}{|c|c|c|c|c|c|c|c|}
\hline $\begin{array}{c}\text { DEM } \\
(\mathrm{m})\end{array}$ & $\begin{array}{c}\mathrm{PA} \\
\left(\mathrm{km}^{2}\right)\end{array}$ & $\begin{array}{c}\mathrm{SA} \\
\left(\mathrm{km}^{2}\right)\end{array}$ & $\begin{array}{c}\text { Ratio } \\
(\%)\end{array}$ & $\begin{array}{c}\text { Slope } \\
\left({ }^{\circ}\right)\end{array}$ & $\begin{array}{c}\mathrm{PA} \\
\left(\mathrm{km}^{2}\right)\end{array}$ & $\begin{array}{c}\mathrm{SA} \\
\left(\mathrm{km}^{2}\right)\end{array}$ & $\begin{array}{c}\text { Ratio } \\
(\%)\end{array}$ \\
\hline$<50$ & 377.90 & 380.09 & 27.28 & $<2$ & 378.53 & 378.62 & 27.18 \\
\hline $\begin{array}{l}50- \\
100\end{array}$ & 183.80 & 184.10 & 13.21 & $2-3$ & 154.68 & 154.82 & 11.11 \\
\hline $\begin{array}{l}100- \\
200\end{array}$ & 136.96 & 138.90 & 9.97 & $3-5$ & 122.72 & 122.99 & 8.83 \\
\hline $\begin{array}{c}200- \\
500\end{array}$ & 369.59 & 390.06 & 28.00 & $5-6$ & 29.84 & 29.97 & 2.15 \\
\hline $\begin{array}{l}500- \\
1000\end{array}$ & 250.68 & 272.90 & 19.59 & $6-8$ & 52.95 & 53.34 & 3.83 \\
\hline $\begin{array}{c}1000- \\
1500\end{array}$ & 23.31 & 27.07 & 1.94 & $8-10$ & 51.30 & 51.94 & 3.73 \\
\hline \multirow{4}{*}{\multicolumn{4}{|c|}{$\begin{array}{l}\text { PA stands for Projected area } \\
\text { SA stands for Superficial area }\end{array}$}} & $10-15$ & 136.47 & 139.84 & 10.04 \\
\hline & & & & $15-25$ & 260.80 & 277.55 & 19.92 \\
\hline & & & & $25-35$ & 134.61 & 154.19 & 11.07 \\
\hline & & & & $>35$ & 20.36 & 29.85 & 2.14 \\
\hline
\end{tabular}

\subsubsection{Ratio of Different land cover types}

From Figure.3, the ratio of crop land shows a decreasing trend from $44.57 \%$ to $15.97 \%$ from 1983 to 2013 , which were mainly replaced by build-up land. The ratio of forest and grass increases slowly, which is guided by series of policy, like conversion of cropland to forest and urban greening. Meanwhile, the ratios of water and other land cover type have no obvious change.

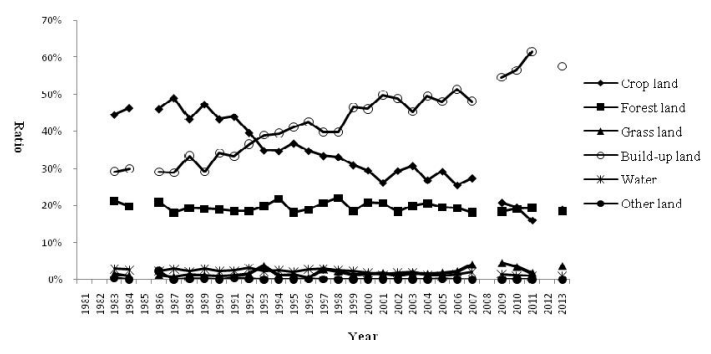

Figure.3 Temporal variation of different land cover ratio by Landsat TM between 1983 and 2013, Haidian District 


\subsubsection{Build-up area}

By determining the boundary of the build-up area, the area and circumferences of the build-up land cover are both increased gradually. Moreover, the growth rate of city area is much larger than its circumferences.

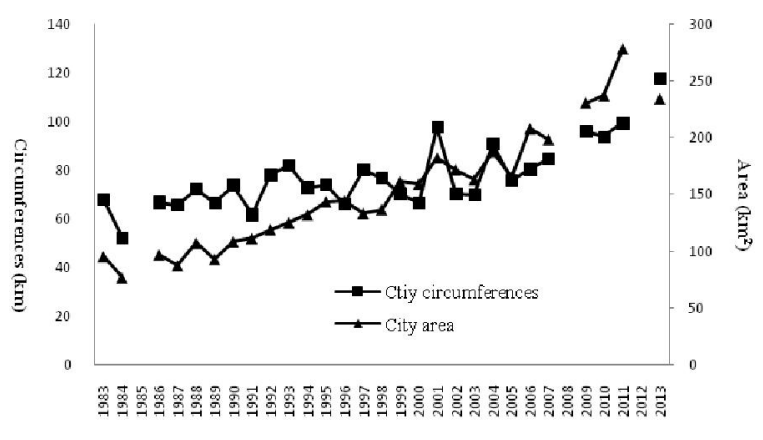

Figure. 4 Temporal variation of city area and circumferences by Landsat TM between 1983 and 2013, Haidian District

\subsection{SUBJECT STATISTICAL INDEXES 4.2.1 Vegetation}

The temporal variations of different land cover types over different elevations are significant (Figure.5a). The changes of crop land and build-up are rapid below $100 \mathrm{~m}$; while forest and grass cover most parts over the regions higher than $200 \mathrm{~m}$. The transition region of vegetation and build-up area locates between $100-200 \mathrm{~m}$, the extent of build-up land is limited by mountain, and its variation is less evident.

Similarly, the temporal variations of land cover types over various slope regions are manifested in Fig.3. Below $10^{\circ}$, the land cover types of forest/grass and built-up area increased rapidly with time, but the grow rate decrease slowly. From Figure.5b, the slope with $5^{\circ}$ is the threshold for crop land and build-up area, so these parts should paid more attention to avoid overexploitation. Meanwhile, the variation of forest over the higher slope areas should be paid more attention to prevent water and soil losses.

(a)
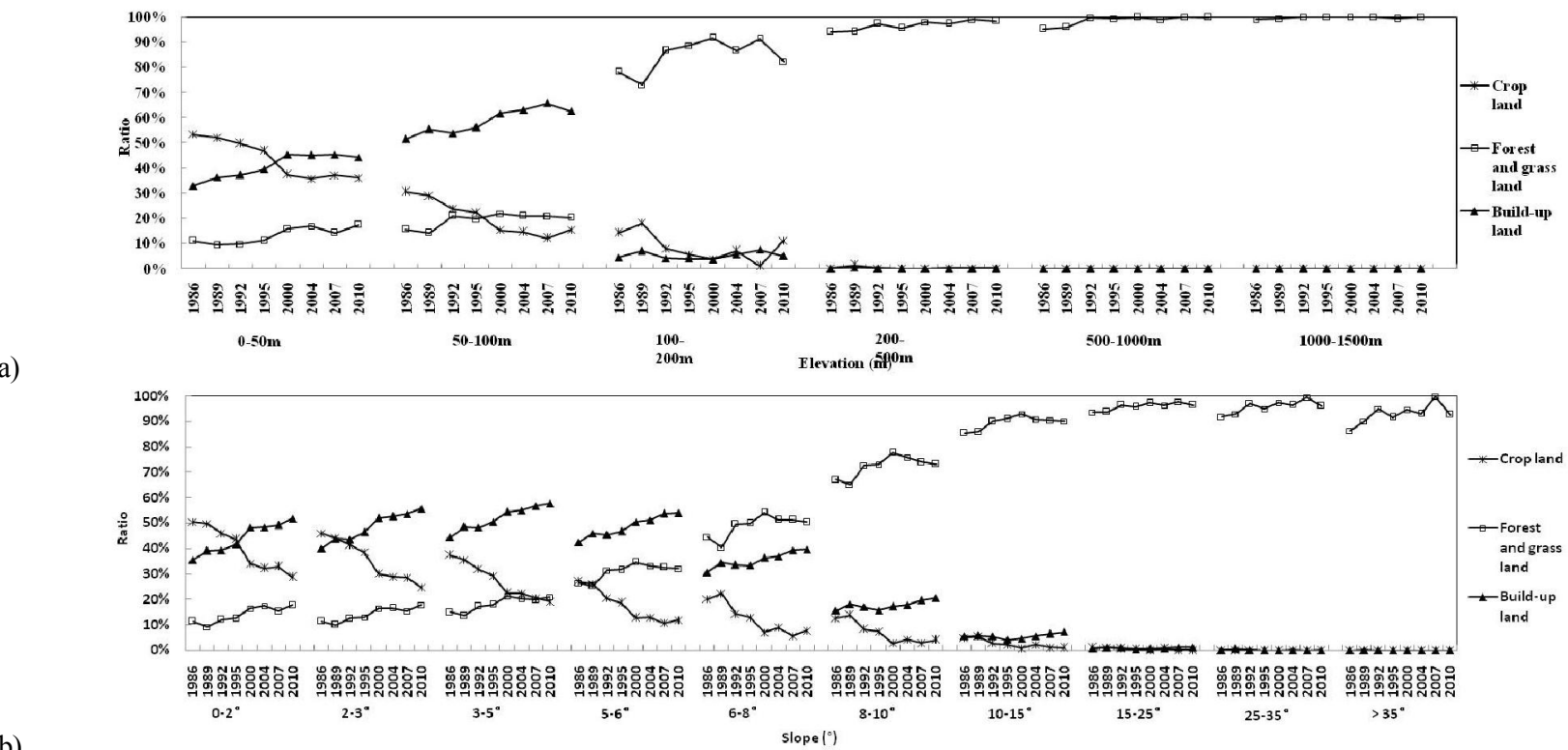

Figure.5 Temporal variation of different land cover percentage by Landsat TM over various elevation (a) and slope (b) range between 1983 and 2013, Haidian District

\subsubsection{Build-up land}

The city ranges for Landsat-series data are determined according to $M u$ et al., (2012). According to Figure.6, the city extension was limited due to the distribution of mountain area in the west part. Thus the city extension was mainly extents to the north and northwest parts by occupying crop land. Meanwhile, the centroid of city was shift towards northwest accordingly (Figure.7).
Both the rate and intensity are the indicators of city extension, and they are positive correlated (Figure.8). In the period between 1989-1992 and 2000-2004, the area of build-up change slightly, the rate and intensity are also close to 0 . The period between 1990 and 2000 is the key stage for Beijing development, social mechanism, social structure changed greatly, the rate and intensity of city extension displayed higher values. 
The theory values of city compact ratio and fractal dimension are between 0 and 1(Figure.9), the larger the index, the city range is more regular, which is the ideal city extension model. Both the two indexes are consistent with the shape variation in Figure.6. During the period between 1992 and 2007, the city extents towards west and north, the city compact ratio and fractal dimension varied less evident. Around 2010, the city extent greatly towards north, which induces the city range are much more irregular than ever.

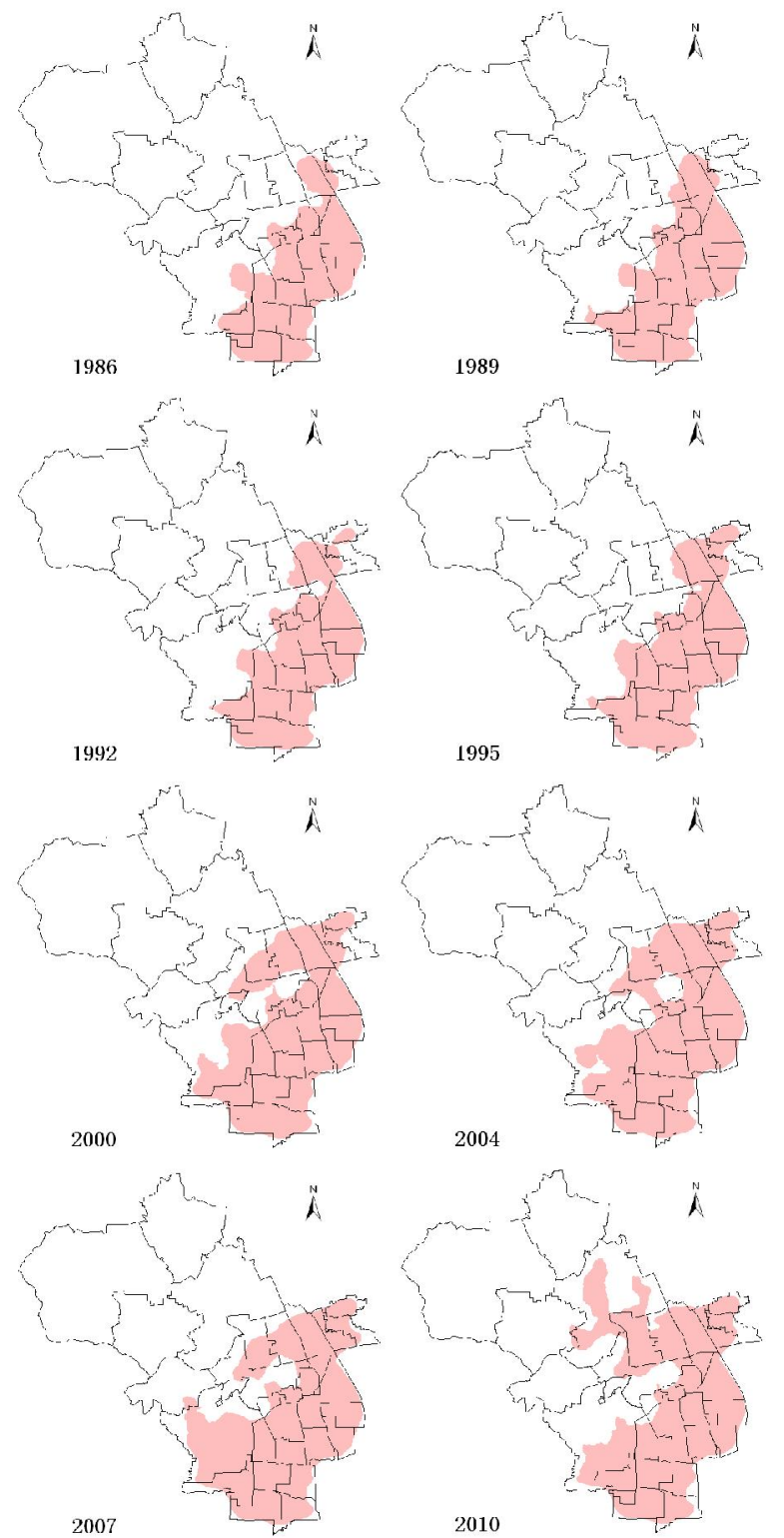

Figure. 6 Temporal-spatial variation of city range by Landsat TM between 1986 and 2010, Haidian District

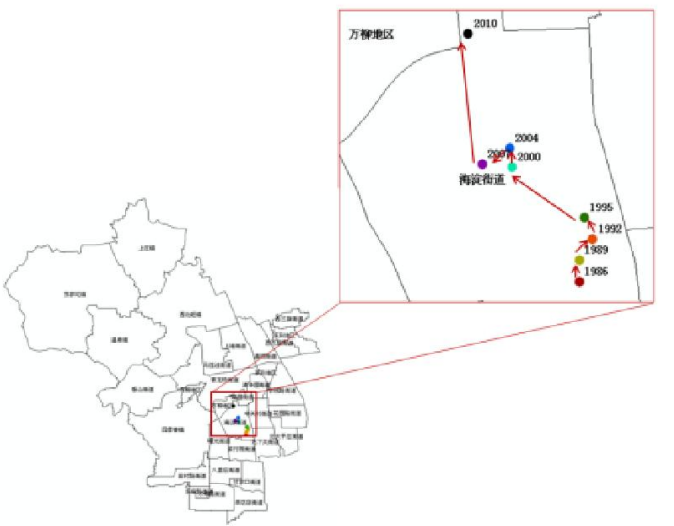

Figure. 7 Trajectories of city centroid by Landsat TM between 1986 and 2010, Haidian District

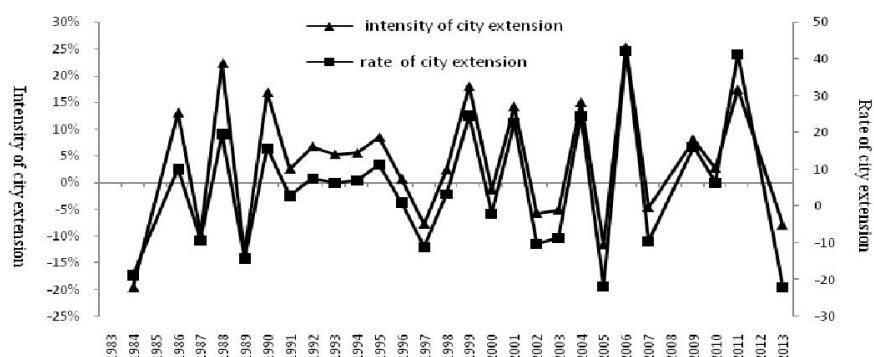

Year

Figure. 8 Temporal variation of the rate and intensity of city extension between 1986 and 2010,Haidian District

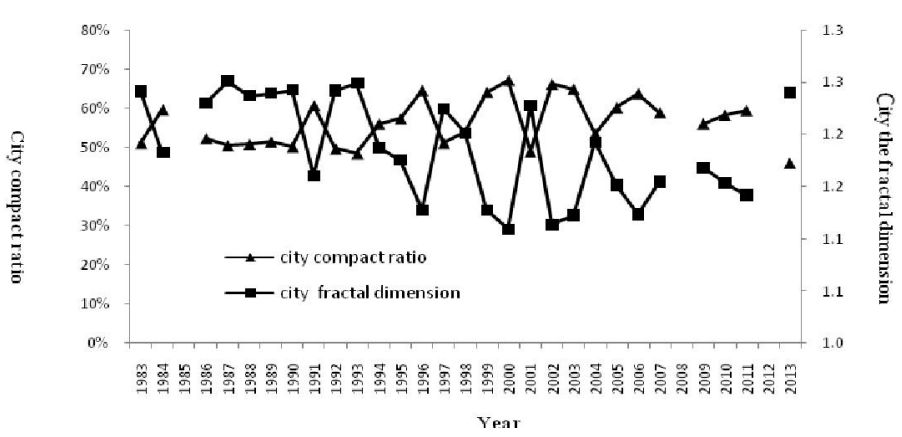

Figure. 9 Temporal variation of the city compact ratio and the fractal dimension between 1986 and 2010,Haidian District

\subsection{COMPOSITE STATISTICAL INDEXES}

\subsubsection{Land cover suitability atlas}

Based on current land cover map in 2013 of Haidian District as basic image, combined with the determinant involved DEM and meteorological phenomena to make various type of land cover suitability atlas in Haidian District with the LogisticReg module of IDRISI (Fig.10).Red represent the highest suitability as well as black represent that the suitability is zero. Forest land distribute in 
western mountain area, build-up land distribute from the south to the central, crop land mainly concentrated in northern plain country.
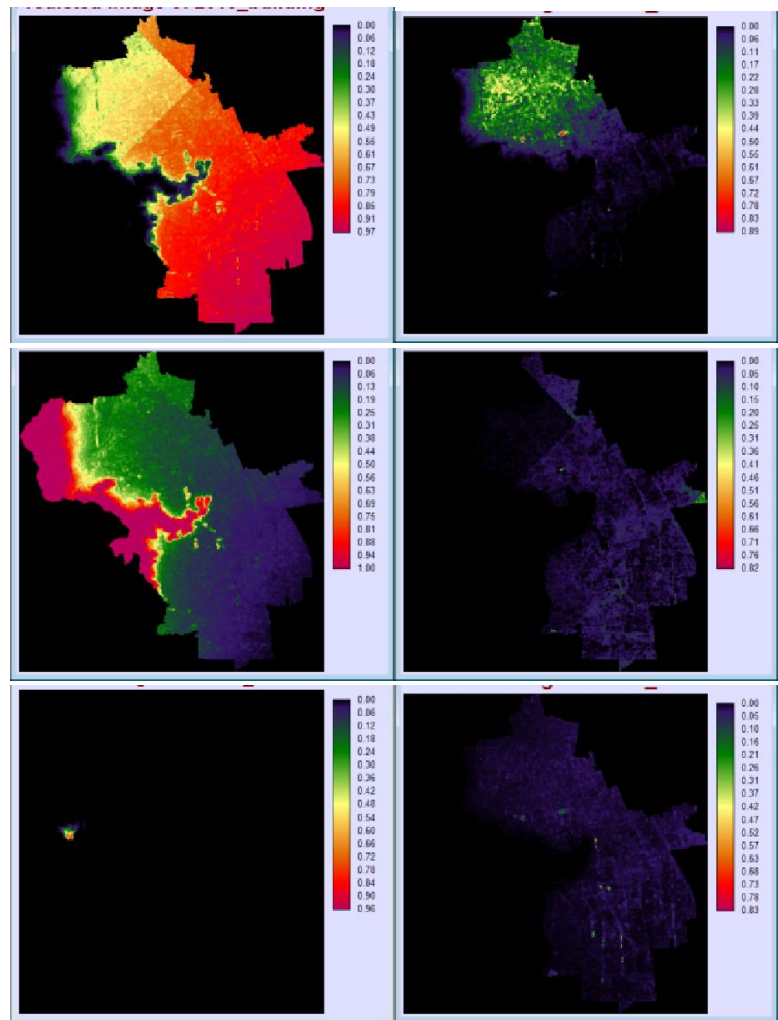

Fig. 10 land cover suitability atlas, Haidian District Exegesis: Turn: build-up land, crop land, forest land, grass land, other land water

\subsubsection{Land covers change prediction}

Based on current land cover map in 2013 of Haidian District as basic image, combined with 2011-2013 land cover transition probability matrix and land cover suitability atlas to predict spatial distribution of land cover change in 2015 with the CA-MARKOV module of IDRISI (Fig.11). The prediction display that except for the increasing of build-up area in the northern plain area, the spatial distribution of different land cover types is similar to 2013.

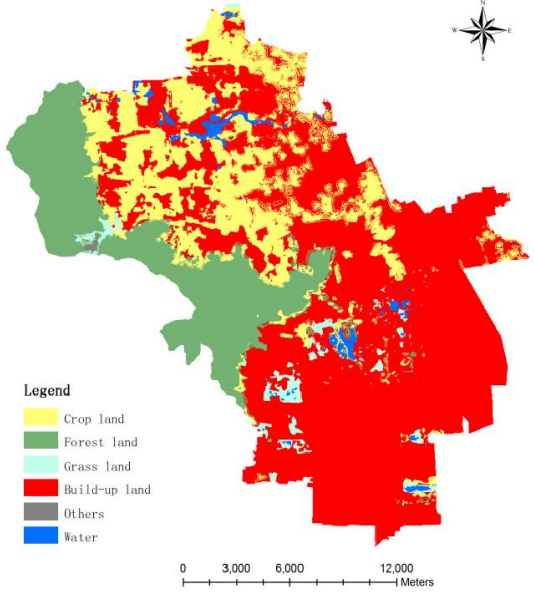

Figure. 11 spatial distribution of prediction land cover in 2015, Haidian District

\subsection{BASIC GEOGRAPHIC ELEMENT STATISTICAL}

By using the administrative units within Haidian District, the variation of different land cover types were calculated from 1983 to 2013. In our paper, some examples were listed below to show the different developed form for varied administrative unit, which hints that specific strategy and planning should be made for different area.
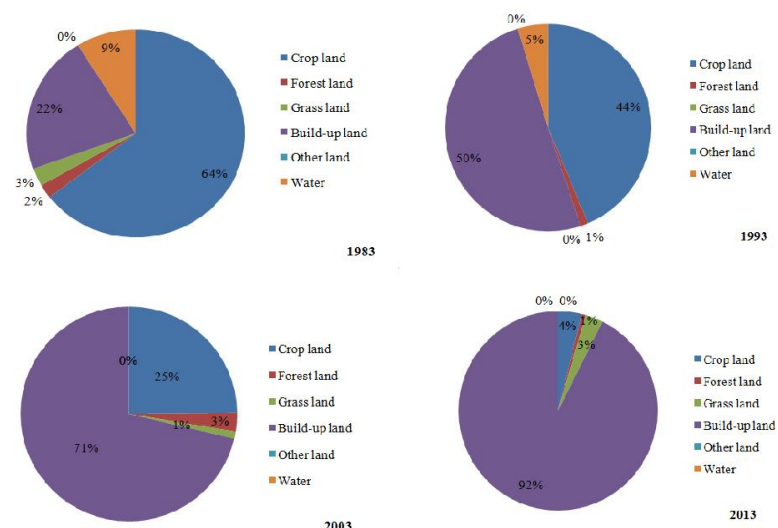

Figure.12 Temporal variation of different land cover ratio by Landsat TM between 1983 and 2013, Malianwa Street 


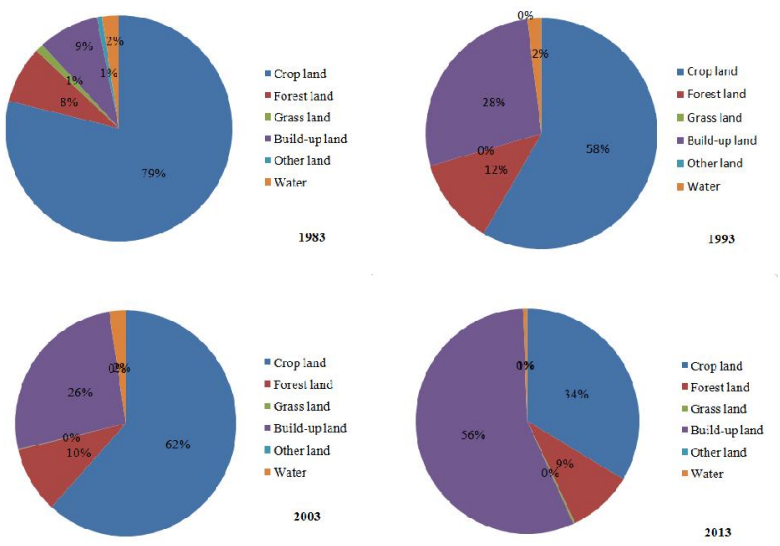

Figure.13 Temporal variation of different land cover ratio by Landsat TM between 1983 and 2013, Xibeiwang Street

\section{CONCLUSIONS}

Based on Landsat-series data, the temporal-spatial variation of national geographic condition in Haidian district is well presented by a systematic index system. From 1983 to 2013, the crop land is gradually replaced by build-up over lower elevation and slope areas. For different development period, the rate and intensity of city extension, as well as the city morphology showed greatly variation, which is consistent with historically social and economic development. Finally, predicting the spatial distribution of land cover in the future with CA-MARKOV model can make a strategic decision for government about city development. Based on such a long time series monitoring data, more prediction analysis could be achieved further, guiding the national strategic decision making and planning.

\section{REFERENCES}

Cai, B.F., Zhang, Z.X., Liu, B., et al., 1997. Spatialtemporal changes of Tianjin urban spatial nophology from 1987 to 2004. Journal of Geographiccal Sciences, 4:500-510.

Mu, X.D., Liu, H.P., Xue, X.J., 2012. Urban Growth in Beijing from 1984 to 2007 as gauged by remote sensing. Journal of Beijing Normal University (Natural Science), 48(1):81-85.

Shi W Z., 2013, Theories and technologies on monitoring for national geographical state, Science Press, pp4.

Wu, J.G., 2000. Landscape Ecology-Pattern, Process, Scale and Hierarchy. Higher Education Press. pp266.

Yu, X.Q., 2010. Beijing Statistical Year Book. China Statistics Press, pp1. 